\title{
Electromiographic signal reliability analysis during maximum and submaximum knee isometric actions
}

\author{
Michel A Brentano \\ Eduardo M Silva \\ Eduardo L Cadore \\ Luiz FM Kruel
}

https://doi.org/10.5628/rpcd.07.03.308

\author{
Exercise Laboratory R esearch \\ Physical Education School \\ Federal University of Rio Grande do Sul \\ Brazil
}

\begin{abstract}
The objective of this paper was to verify the reliability of the amplitude of the EMG signal of the vastus lateralis muscle (VL) in the right thigh, in different occasions, during maximum and submaximum knee extensors isometric actions. Three people performed the following protocol: execution of 3 maximum voluntary isometric contractions (MVCs) during $3 \mathrm{~s}$ each, with later execution of submaximum actions (20, 40, 60 and $80 \%$ of the MVC), calculated considering the MVC of the highest torque peak. Each submaximum contraction (SC) lasted $4 \mathrm{~s}$ and was kept through a visual feedback (oscilloscope). Between each MVC and among the SC a 2 min gap was given. Parallel to the actions, EMG signal of the VL muscle was obtained through the surface electrodes put on the muscle venter longitudinally to the direction of the fibers. A reference electrode was positioned in the tuberosity of the tibia. To attest the same position among the sampling the site of the electrodes was marked with a pen for retroprojector. The same protocol was performed after 48hs for reliability analysis. Such analysis was made through Pearson correlation, with significance $p<0.05$. After signal processing and comparison of root mean square values, obtained in the test and re-test, it was found a high correlation among these values $(r=0.972$, $\mathrm{p}<0.01$ ). These results suggest the reliability of the EMG signal, which would make its usage available for investigations that aim at comparing its amplitude in acquisitions performed in different occasions.
\end{abstract}

K ey-words: electromiography, reliability, isometric actions.
RESUMO

A nálise da reprodutibilidade do sinal electromiográfico durante acções isométricas máximas e submáximas dos extensores do joelho

A amplitude do sinal eletromiográfico (EM G) tem sido utilizada para relacionar a ativação das unidades motoras com sua produção de força, durante um período de treinamento. A validade dessas mensurações é discutida devido algumas limitações da técnica, da eletromiografia de superfície, que acarretariam na dificuldade de reproduzir o sinal EMG, em diferentes aquisições. A ssim, o objetivo do estudo foi verificar a reprodutibilidade da amplitude do sinal EM G do músculo vasto lateral (VL) da coxa direita, em diferentes ocasiões, durante ações isométricas máximas e submáximas, dos extensores do joelho. Três indivíduos realizaram o seguinte protocolo: execução de 3 contrações voluntárias isométricas máximas (CVM s), durante $3 \mathrm{~s}$ cada, com posterior ex ecução de contrações submáximas $(20,40,60$ e $80 \%$ da CVM ), calculadas a partir da CVM de maior pico de torque. Cada contração submáxima (CS), teve a duração de 4 s e foi mantida através de um feedback visual (osciloscópio). Entre cada CVM e entre as CS foram ministrados 2 min de intervalo. Paralelamente às contrações, 0 sinal EM G do músculo VL foi obtido através de eletrodos de superfície colocados no ventre muscular, longitudinalmente à direção das fibras. U m eletrodo de referência foi posicionado na tuberosidade da tíbia. Para certificar o mesmo posicionamento entre as coletas, o local dos eletrodos foi marcado com caneta tipo "retroprojetor". 0 mesmo protocolo de teste foi realizado após $48 \mathrm{hs}$ para análise da reprodutibilidade. Tal análise foi realizada através da correlação de Pearson, com significância, $p<0,05$. A pós 0 processamento do sinal e comparação dos seus valores root mean square, obtidos no teste e re-teste, verificou-se uma alta correlação entre esses valores $(r=0,972, p<0,01)$. Esses resultados sugerem a reprodutibilidade do sinal EM G, o que possibilitaria a sua utilização em investigações que visem à comparação de sua amplitude em aquisições realizadas em diferentes ocasiões.

Palavras-chave: eletromiografia, reprodutibilidade, ações isométricas 


\section{INTRODUCTION}

Eletromiography (EMG) is the study of the muscular function through the electric signal sent by the mus$\mathrm{cle}^{(2)}$. The Surface Electromiography Technique has been broadly used in the search of quantification of the total amount of the potentials of muscle action, represented by the amplitude of the EMG signal and by its correlations to the process of muscle strength generation $(3,9)$.

It is well known that the amplitude of the EMG signal is related to a certain extent to the strength that the muscle can produce. The characteristic of this relationship between strength $x$ EMG is not completely understood. Moritani and DeVries(11), Woods and Ritchie(18), Lawrence and De Luca(10), Narici et al.(12) and Sbricolli et al. (16), registered a linear correlation between the values of the amplitude of the EMG signal and the isometric strength of muscles such as the biceps brachii, the vastus lateralis, the soleous among others. On the other hand, Wood and Richtie (17) and Lawrence and DeLuca(9) identified a curvilinear relationship to muscles such as the triceps brachii and the deltoid. So, it seems that the characteristic of the existing relationship between the amplitude of the EMG signal and the strength is directly dependent on the evaluated muscle.

Considering the existing relationship between the strength and the EMG signal, several authors started to use the Surface Electromiography technique to the study of neuromuscular adaptations, during a period of strength training(5,6). Once the amplitude of the EMG signal is determined by the frequency of muscular activation and by the number of recruited motor units, the increase in the amplitude of the EMG signal after training might suggest the existence of neural adaptations occurred with the training(7). However, the validity of this analysis is widely disputed due to some limitations of the technique, which would make the reproducibility of the EMG signal difficult(3).

That being so, the objective of this study was to verify the possibility of reproducing the EMG signal during maximum and submaximum isometric actions of the knee extensors in the vastus lateralis (VL) of the right thigh.

\section{MATERIALS AND METHODS}

Subjects

Three young physically active individuals, of 20, 22 and 25 years of age, without skeletal-muscle limitations, currently studying at the Physical Education School of the Federal University of Rio Grande do Sul (UFRGS) were invited to take part in the study.

Preparation of the individuals

In a first moment, the individuals were gathered in the Laboratory of Research in Exercise at UFRGS where the experimental procedures were explained and doubts were solved.

Later on, in order to acquire the EMG signal, shaving and cleaning the skin with cotton moisted in alcohol gel was necessary for the applying of the electrodes. The surface electrodes were then positioned in bipolar configuration, longitudinally to the direction of the muscular fibers, in the venter of the vastus lateralis towards the muscular fibers, according to the recommendation proposed by Basmajian \& Deluca(2), Deluca(3) and Pincivero et al.(14). The distance between the electrodes is set in $2 \mathrm{~cm}$, typical of the model of electrode used (NORAXON, model \#242) and, between the two samples, the impedance level between the electrodes was measured, controlled and kept below 3,000 Ohms(12), through the verification made by a multimeter. A reference electrode was put on the front face of the tibia. The position of the electrodes was marked in the skin with a marker for retroprojector in order to assure the same position of the electrodes between the two samples(4).

Isometric Protocol

After the preparation and positioning of the electrodes, each individual warmed-up using a bicycle ergometer, with light intensity during 5 minutes. Then they went to the chair of the isokinetics dynamometer where they were attached by bands that crossed their torax and pelvis. Hips and knees stayed in angles of 110 and 107 degrees respectively(7) and the knee articulation was lined with the rotation axis of the dynamometer. In the protocol, similar to the one used by Moritan \& DeVries (11) and Rabita et al. (15), 3 maximum voluntary contractions were performed (MVCs) each one being of 3 seconds. 
The MVC with the highest torque peak was used to calculate the different percentages of the submaximum isometric strength $(20,40,60$ and $80 \%$ of CVM), which were lately executed for 4 seconds and kept through the visual feedback, given by an oscilloscope. Between each MVC and among the four submaximum contractions 2 minutes' break periods were made to avoid muscle fatigue effects. The same protocol was executed 48 hours after the first acquisition to verify the reproducibility of the signal.

The torque $(\mathrm{Nm})$ of the knee extensors muscles was obtained through the values registered by the dynamometer and transmitted simultaneously to the EMG signal collected by the electromiographer, to the CODAS program of data acquisition and to the oscilloscope in order to make the visualization of the different percentages of the MVC possible. The acquisition of the torque curves $\left(E M G_{\text {vlat }}\right)$ was made using a sampling frequency of $2.000 \mathrm{~Hz}$ (2) and specifically to the signal EMG gains ranging between 1.000 and $2.000 \mathrm{~K}$ were used.

Treatment of the torque data

In each evaluation, the torque curves and the signal EMG of the VL muscle were saved in a continuous file. After the samples were gathered, the different percentages of the isometric strength were identified through the plateaus produced during the protocol. Immediately, each percentage was classified in order to produce independent files (ex: 20,40, $60,80 \%$ and MVC) for later analysis in the SAD2(32bits) $2.61 .05 \mathrm{mp}$ data acquisition system elaborated in the Laboratory of Mechanic Measurements at the UFRGS. After the classification the five files of each individual were imported in the SAD2 data acquisition system for the processing of the curves. So, the torque curves were filtered with a butterworth filter of 9th order with cut-off frequencies ranging from 0 to $9 \mathrm{~Hz}$.

The torque curves preserved the unit used in their acquisition, in this case, volts (V). So, after the filtering process in the file with maximum torque, it was identified the point of maximum torque production, in order to calculate the values of the curves that should be used as reference for the classification of the EMG signals of the VL muscle in the respective percentages of the MVC $(20,40,60$ and $80 \%)$.
EMG Signal analysis

After the import of the curves in the SAD2 data acquisition system, the following treatment of the EMG signal was performed: 1- removal of the continuous components; 2 - removal of the gains used in the acquisition process; 3- filtering of the signal with a filter of butterworth of $5^{\text {th }}$ order and cut-off frequencies ranging from 20 to $500 \mathrm{~Hz}$; 4- filtering of the signal with a filter via FFT of the kind "removes automatic peaks", with average bandwidth and ratio of 30 and 2 respectively; 5- identification, in the EMG, of the corresponding place to the torque curve equivalent to the level of effort made; 6 - generation of windows with 1 second in the EMG signal in the point previously identified; 7- generation of "envelopes" root mean square (rms) with gaps of 50 $\mathrm{ms}$, in windows previously created; and 8- identification of the average values of each "envelope" RMS, that were used as representative values of each EMG curve, in the different levels of voluntary effort. The filtering procedures follow the proposed recommendation by DeLuca(3), while the classifying and quantification were similar to the ones used by Pincivero et al.(14).

\section{Statistical Analysis}

A statistical package SPSS version 11.0 was used for data comparison. Descriptive statistics was also used. The normality and homogeneity were analyzed through tests of Shapiro-Wilk and Levene respectively. The reliability of the signal was proved to be true with the test of Pearson intra-class correlation, and the level of significance was considered $\mathrm{p}<0.05$.

RESULTS

Table 1 presents the values rms EMG obtained by the different individuals with the respective levels of isometric effort required in the first and in the second sampling. 
Table 1. Values rmsEMG on the different days of sampling ( 1 and 2 ) obtained from the different individuals $(1,2$ and 3$)$ in the respective levels of required isometric effort (MVC, 80, 60, 40 and 20\%).

\begin{tabular}{lccl}
\hline & $\begin{array}{c}\text { rmsEMG 1 } \\
\text { values (mV) }\end{array}$ & $\begin{array}{c}\text { rmsEMG 2 } \\
\text { values (mV) }\end{array}$ \\
\hline MVC & 0.39 & 0.38 & Individual 1 \\
MVC & 0.39 & 0.4 & Individual 2 \\
MVC & 0.49 & 0.48 & Individual 3 \\
$80 \%$ & 0.34 & 0.3 & Individual 1 \\
$80 \%$ & 0.26 & 0.35 & Individual 2 \\
$80 \%$ & 0.33 & 0.35 & Individual 3 \\
$60 \%$ & 0.25 & 0.2 & Individual 1 \\
$60 \%$ & 0.21 & 0.23 & Individual 2 \\
$60 \%$ & 0.24 & 0.26 & Individual 3 \\
$40 \%$ & 0.14 & 0.13 & Individual 1 \\
$40 \%$ & 0.11 & 0.14 & Individual 2 \\
$40 \%$ & 0.13 & 0.15 & Individual 3 \\
$20 \%$ & 0.06 & 0.05 & Individual 1 \\
$20 \%$ & 0.07 & 0.07 & Individual 2 \\
$20 \%$ & 0.07 & 0.08 & Individual 3 \\
\hline & rmsEMG, electromiographic root mean square; \\
& MVC, maximum voluntary contraction; mV, milivolts.
\end{tabular}

Figure 1 shows the existence of a high correlation ( $r=0.972, p>0.01$ ) among $r m s$ values of the EMG signal of the VL muscle obtained in the 2 evaluations.

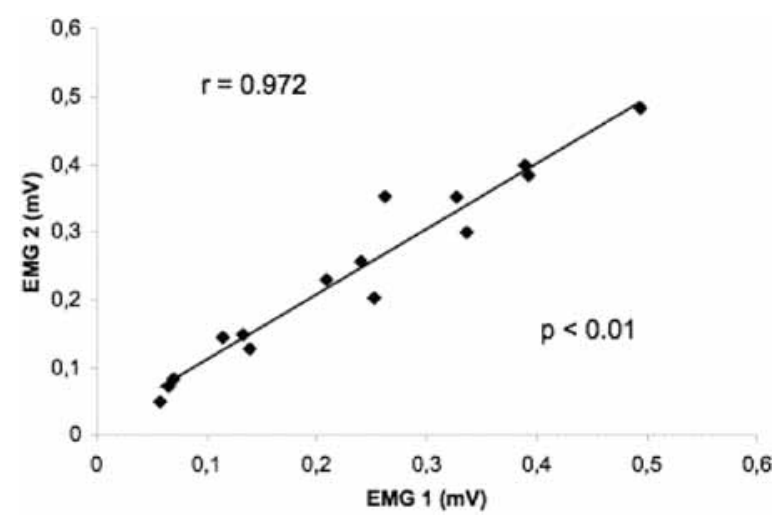

Figure 1. Values $\mathrm{rms}(\mathrm{mV}$ ) of the electromiographic signal of the VL muscle, obtained in the first (EMG1) and in the second (EMG2) evaluation.

\section{DISCUSSION}

Reported data about the reproducibility of the EMG signal are controversial when small gaps between test and re-test have been accessed(1,17,18). The results obtained in the present study suggest the possibility of reproducing the EMG signal of the VL muscle with great reliability in short gaps between one sampling and the other one. Moritan \& DeVries(11) in similar methodological approach had registered good reproducibility of the EMG signal $(r=0.998 ; p<0.001)$, in the biceps brachii muscle in young men and women. Later on, analyzing the effects of strength training about neural adaptation of the individuals, Hartobágyi et al.(8) verified the reproducibility of the EMG signal in the vastus lateralis muscle in young Caucasian people. This author found a high correlation ( $r=0.96)$ among the acquisitions performed, however the study does not show the protocol used. Bamman et al.(1) observed high ICC between EMG values obtained among 5 days ( 0.71 to 0.90 ), in three superficial quadriceps muscles: rectus femoris, vastus medialis e vastus lateralis. Viitasalo e Komi (18) showed similar values ( 0.77 to 0.93 ) in rectus femoris, however they observed higher reproducibility of measurements within the test session than between different days.

The present study showed high levels of reproducibility between EMG signals obtained of vastus lateralis muscle. Because no difference was observed in peak torque between days, the increased day-today variability in EMG was not likely due to a torque-dependent source of error (e.g. subject motivation). Sources of measurement error that could account for differences between test days include electrode position and skin preparation; however, these were controlled in our study.

Although evidences that the EMG signal can be reproducible in different acquisitions, in a recent study Kolmitzer et al.(9), verified that different gaps of time among the acquisitions could influence the reliability of the signal of the rectus femoris muscle. When the gap of time among the samplings was just 3 minutes, the presented correlation was too high $(r=0.999)$. After a 90-minute gap the correlation kept high $(r=0.945)$. However, when the gap among the samplings was of six weeks, although the correlation had kept high $(r=0.871)$ it was significantly smaller when compared to the previous correlations. That's why caution is suggested while analyzing the amplitude of the EMG signal in acquisitions made with long gaps of time. In this case some care must be taken concerning the positioning of the electrodes, mainly in studies that evaluate the rehabilita- 
tion or the muscular training, once long periods of time between the test and the re-test are necessary.

\section{CONCLUSION}

The reliability of the EMG signal in the vastus lateralis muscle in maximum and submaximum levels of voluntary isometric effort seems feasible in short periods among different acquisitions. This could make its use possible in investigations that aim at comparing the amplitude of this signal in different occasions.

\section{CORRESPONDENCE}

\section{Michel Arias Brentano}

Rua: Felizardo, № 750

Bairro: Jardim Botânico

\section{C.P.: $90690-200$}

Escola de Educação Física/ LAPEX sala 208

Porto Alegre, RS

Brazil

E-mail: michel.brentano@terra.com.br

\section{REFERENCES}

1. Bamman M, Ingram S, Caruso J, Greenisen M (1997) Evaluation of surface electromyography during maximal voluntary contraction. J Strength Cond Res 11: 68 - 72.

2. Basmajian, De Luca. M uscle A live: their functions revealed by electromyography, 5th ed. Baltimore. Williams \& Wilkins, 1985.

3. De Luca CJ (1997). The use of electromyography in biomechanics. J A ppl Biomec 13: 135-163.

4. Hakkinen K, Komi PV (1983). Electromyographic changes during strength training and detraining. M ed Sci Sports Exerc 15(6): $455-460$

5. Hakkinen K, Alen M, Kallinen M (1998a). Muscle CSAforce production, and activation of leg extensors during isometric and dinamic actions in middle-aged and older people. JAPA 6: 232-247.

6. Hakkinen $\mathrm{K}$, Kallinen M, Izquierdo M, Jokelainen K Lassila H, Mälkiä E, Kraemer WJ, Newton RU, Alen M (1998b). Changes in agonist-antagonist EMG, muscle CSA, and force during strength training in middle-aged and older people. J A ppl Physiol 84: 1341-1349.

7. Hakkinen K, Alen M, Kallinen M, Newton RU, Kraemer WJ (2000). Neuromuscular adaptation during prolonged strength training, detraining and restrength-training in middle-aged and elderly people. Eur J A ppl Physiol 83: 51-62.

8. Hortobágyi T, Hill JP, Houmard JA, Fraser DD, Lambert NJ, Israel RG (1996). Adaptative responses to muscle lengthening and shortening in humans. J A ppl Physiol 80: 765-772.

9. Kollmitzer J, Ebenbichler GR (1999). Kopf, A. Reliability of surface eletromyographic measurements. Clin N europhysiol 110: 725-734.

10. LawrenceJH, Deluca CJ (1983). Myoeletric signal versus force relationship in different human muscles. J A ppl Physiol 54: 1653-1659.

11. Moritani T, De Vries HA (1978). Reexamination of the rela tionship between the surface IEMG and force of isometric contraction. A m J Phys M ed 57: 263-277.

12. Narici MV, Roi GS, Landoni L, Minetti, AE, Cerretelli $P$ (1989). Changes in force, cross-sectional area and neural activation during strength training and detraining of the human quadriceps. Eur J A ppl Physiol 59: 310-319.

13. Narici MV, Hoppeler H, Kayser B, Landoni L, Claassen H, Gavardi C, Conto M, Cerretelli P (1996). Human quadriceps cross-sectional area, torque and neural activation during 6 months strength training. A cta Physiol Scand 157: 175-186.

14. Pincivero DM, Campy RM, Salfetnikov Y, Bright A, Coelho AJ (2001) Influence of contraction intensity muscle, and gender on median frequency of the quadriceps femoris. J A ppl Physiol 90: 804-810.

15. Rabita G, Pérot C, Corbeil GL (2000). Differential effect of knee extension isometric training on the different muscles of the quadriceps femoris in humans. Eur J A ppl Physiol 83: 531-538.

16. Sbriccoli, P, Bazzucchi I, Rosponi A, Bernardi M, Devito G, Felici $F$ (2003). Amplitude and spectral characteristics of bíceps brachii SEMG depend upon speed of isometric force generation. J Electrom Kinesiol 13: 139-147.

17. Thorstensson A, Larsson L, Tesch P, Karlsson J (1977). Muscle strength and fiber composition in athletes and sedentary men. M ed Sci Sports 9: 26-30.

18. Viitasalo J, Komi P (1975). Signal characteristics of EMG with special reference to reproducibility of measurements. Acta Physiol Scand 93: 531-539.

19. Woods JJ, Ritchie BB (1982). Linear and non - linear surface $\mathrm{EMG} /$ force relationships in human muscles. A m J Phys M ed 62: 287-299. 